\title{
Analysis of Fatigue and Microhardness in Metallic Powder Mixed EDM
}

\author{
Alexis Mouangué Nanimina ${ }^{*}$, Nandiguim Lamaï1, Djimako Bongo ${ }^{1,2}$, Togdjim Jonas ${ }^{1}$, \\ Bonaventure Danoumbé1, Ahmad Majdi Abdul-Rani ${ }^{3}$
}

\author{
${ }^{1}$ Mechanical Engineering Department, Higher National Institute of Sciences and Techniques of Abéché (INSTA), Abéché, \\ Ouaddai, Chad \\ ${ }^{2}$ Higher Normal School of Technology of Sarh, Moyen-Chari, Chad \\ ${ }^{3}$ Mechanical Engineering Department, Universiti Teknologi PETRONAS (UTP), Perak, Darul Ridzuan, Malaysia \\ Email: *alexisnanichad@gmail.com
}

How to cite this paper: Nanimina, A.M., Lamaï, N., Bongo, D., Jonas, T., Danoumbé, B. and Abdul-Rani, A.M. (2020) Analysis of Fatigue and Microhardness in Metallic Powder Mixed EDM. Open Journal of Applied Sciences, 10, 613-624.

https://doi.org/10.4236/ojapps.2020.1010043

Received: August 28, 2020

Accepted: October 10, 2020

Published: October 13, 2020

Copyright (c) 2020 by author(s) and Scientific Research Publishing Inc. This work is licensed under the Creative Commons Attribution International License (CC BY 4.0)

http://creativecommons.org/licenses/by/4.0/

\begin{abstract}
The objective of this work research is to investigate the potential of using metallic powder mixed with electrical discharge machining (EDM) dielectric when machining hard electrically conductive materials. Nowadays, the development of industries requires hard materials for various applications. Machining the hard materials using the traditional processes lead to tool break and poor machined product. Even when the conventional EDM can machine hard material as long as it is electrically conductive materials, the machined parts still present drawbacks. Metallic powder mixed with EDM dielectric (PMEDM) was hypothesized to improve the machined part. The presence of metallic powder ensures uniform distribution of spark and the electrical density of the spark decreases which reduces craters, cracks and voids on machined surface. The transfer and deposit of alloying elements during powder mixed electrical discharge machining improve the machined surface properties particularly micro-hardness and fatigue. Discharge current (IP), gap voltage (GapV), ON-time $(\mathrm{ON})$ and aluminum powder are selected as machined variable parameters and the output responses are fatigue performance, micro-hardness and surface topography. The workpiece material selected is molybdenum high speed steel. Micro-hardness was determined using micro-hardness tester device. The fatigue performance was determined using empirical equation. Analysis of material transfer was done using energy dispersive spectroscopy (EDS) attached to FESEM. EDS analysis involves the generation of an X-ray spectrum from the entire scan area of the SEM. The use of PMEDM improved the fatigue, the micro-harness and the machined surface morphology as the above-mentioned parameters increased.
\end{abstract}




\section{Keywords}

PMEDM, Fatigue, Micro-Hardness, Discharge Current, Gap Voltage,

ON-Time

\section{Introduction}

Metallic powder is added to dielectric fluid and it fills up the gap between the electrode and workpiece as shown in Figure 1. When potential difference is applied between the electrode and workpiece, an electric field between $105-107$ $\mathrm{V} / \mathrm{m}$ will be generated. Metallic powder particles under machining zone get energized and form a bridge between the electrode and workpiece as shown in Figure 2. The energy of the conductive particle promotes the breakdown of dielectric fluid and increases the gap with between the electrode and workpiece. Hence, early discharges start under the electrode area and create fast sparks

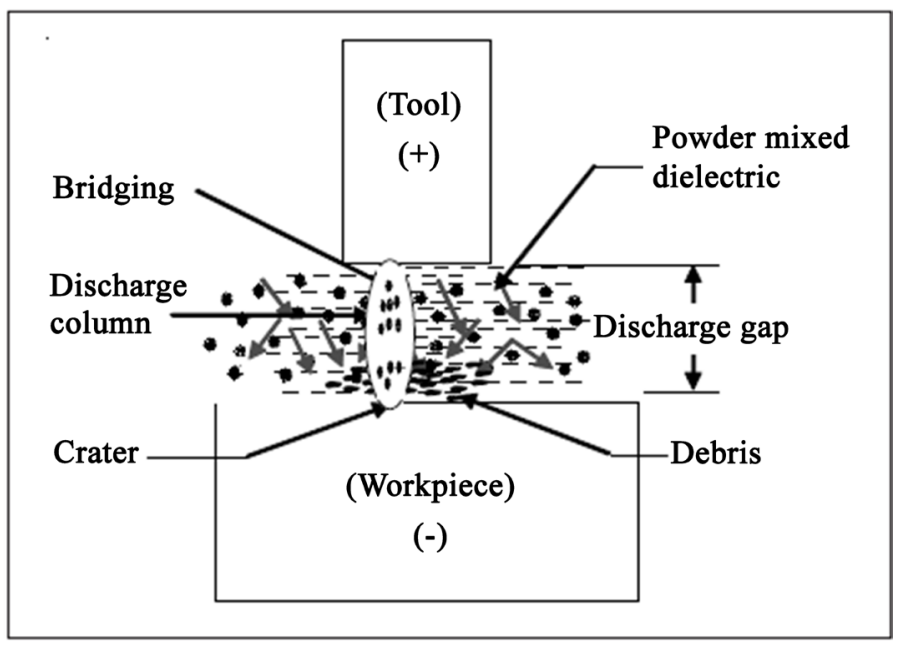

Figure 1. Schematic diagram of PMEDM [1].

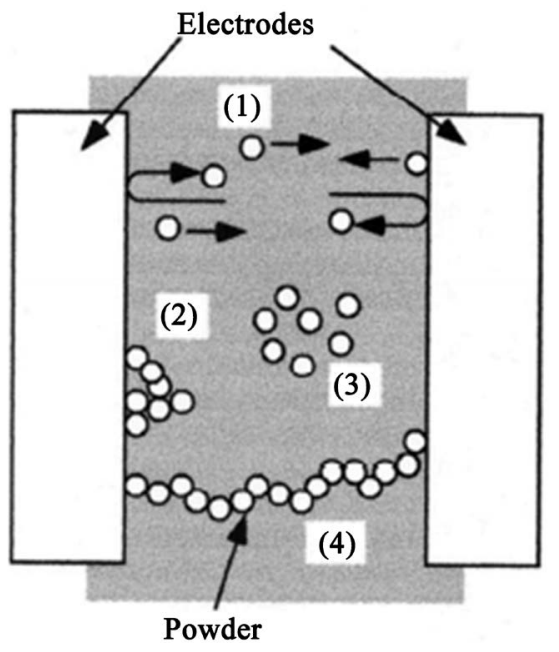

Figure 2. Comportment of metallic powder in the discharge [2]. 
which erode the workpiece. The presence of metallic powder ensures uniform distribution of spark and the electrical density of the spark decreases which improves the machined surface properties.

Some researchers found that accumulation of sparks between two consecutive metallic powder particles in machining area results in series of discharges [3] [4] [5] [6] [7]. This increases the sparking intensity within discharges leading to faster erosion from the workpiece, and therefore increases MRR and the machined surface properties.

The PMEDM process involves the use of different types of conductive or semi-conductive powders mixed with dielectric fluid in attempt to improve the EDM performance [8] [9]. Metallic powder suspended in EDM dielectric fluid is another means of improving the machined surface properties. PMEDM facilitates EDM ignition phases creating higher discharge leading to low dielectric fluid breakdown strength [10] [11].

The limitations of EDM include long lead time to design and fabricate the electrode; relative electrode wear, and undesirable cracks, craters and voids; difficulty in starting the process with very clean dielectric.

Besides, excessive debris in the spark gap can result in arcing causing lack of a precise feeding mechanism and thus, leading to an unstable of EDM performance. In spite of the advantages, PMEDM has certain limitations in production application and these include effective separation of debris from the powder mixed with working fluid; powder distribution requires more investigation; high powder concentration poses a concern. The research is still ongoing in order to overcome the drawbacks of PMDEM [12] [13] [14] [15] [16].

In this research work, discharge current (IP), gap voltage (GapV), ON-time $(\mathrm{ON})$, aluminum powder is selected as machined variable parameters and the output responses are fatigue performance, micro-hardness and surface topography when machining molybdenum high speed steel.

\section{Materials and Methods}

The following sections have presented the devices and machines used.

\subsection{Experiment Set-Up}

Molybdenum high speed steel specifically SKH51 according to Japanese industrial Standards (JIS) designation is selected as the workpiece material. For the specimen preparation, CNC EDM Wire-cut machine FA10 brand was used to cut the raw material into block shape to the size of $9 \mathrm{~mm} \times 11 \mathrm{~mm} \times 5 \mathrm{~mm}$ required for clamping on EDM die sinker EA8. Table 1 presents the chemical compositions of molybdenum high speed steel materials and the work properties of the workpiece material are presented in Table 2.

Copper-tungsten (W70Cu30) was used as electrode material with cross-section of $9 \mathrm{~mm} \times 9 \mathrm{~mm}$. The selection of copper-tungsten is due to good conductivity of copper and good melting point of tungsten. High electrical conductivity of 
electrode promotes more electrons from electrode since electric current is the "cutting tool" and high melting point of electrode contribute low wear ratio since EDM is a thermal process. Combination of copper-tungsten gives optimal electrical and thermal conductivities to the electrode. Table 3 presents copper and copper-tungsten properties.

Nano aluminum powder was selected and each is mixed separately with dielectric fluid during PMEDM. The selection of nano aluminum metallic powder was done by considering the expected contribution of metallic powder to the PMEDM process in terms of electrical conductivity, thermal conductivity, density and melting point properties. The properties of nano aluminum powder are presented in Table 4.

\subsection{Fatigue Performance Measurement}

Fatigue is the progressive and localized structural damage that occurs when a material is subjected to cyclic loading. During EDM or PMEDM the repeated electric sparks causes fatigue damage [17]. Fatigue damage includes three stages such as crack initiation, crack propagation and final fracture. Fatigue of material can also be represented by hardness and some authors have established empirical correlation between hardness and fatigue and ultimate strength in steel as shown in Equation (1) and Equation (2) [18].

$$
\sigma_{w}= \pm 1.6 \mathrm{HV} \text {. }
$$

Table 1. Composition of molybdenum high speed steel.

\begin{tabular}{ccccccccc}
\hline Elements & $\mathrm{C}$ & $\mathrm{Si}$ & $\mathrm{Cr}$ & $\mathrm{V}$ & $\mathrm{W}$ & $\mathrm{Mo}$ & $\mathrm{Co}$ & $\mathrm{Fe}$ \\
\hline Weight (\%) & 0.83 & 0.35 & 3.75 & 1.18 & 1.75 & 8.70 & - & Balance \\
\hline
\end{tabular}

Table 2. Properties of workpiece materials.

\begin{tabular}{ccccccc}
\hline Materials & $\begin{array}{c}\text { Melting } \\
\text { Point }\left({ }^{\circ} \mathrm{C}\right)\end{array}$ & $\begin{array}{c}\text { Density } \\
\left(\mathrm{g} / \mathrm{cm}^{3}\right)\end{array}$ & $\begin{array}{c}\text { Young } \\
\text { modulus } \\
\mathrm{GPa}\end{array}$ & $\begin{array}{c}\text { Thermal } \\
\text { conductivity } \\
\mathrm{W} / \mathrm{m} \cdot \mathrm{K}\end{array}$ & $\begin{array}{c}\text { Hardness } \\
(\mathrm{HB})\end{array}$ & $\begin{array}{c}\text { Electrical } \\
\text { resistivity } \times \\
10^{-7}\end{array}$ \\
$\begin{array}{c}\text { Molybdenum high } \\
\text { speed steel }\end{array}$ & 1082.0 & $7.72-8$ & $190-210$ & 19.0 & 111.0 & 0.6 \\
\hline
\end{tabular}

Table 3. Copper-tungsten (W70Cu30) properties.

\begin{tabular}{ccccccc}
\hline Material & $\begin{array}{c}\text { Melting Point } \\
\left({ }^{\circ} \mathrm{C}\right)\end{array}$ & $\begin{array}{c}\text { Density } \\
\left(\mathrm{g} / \mathrm{cm}^{3}\right)\end{array}$ & $\begin{array}{c}\text { Young } \\
\text { modulus } \\
\left(\mathrm{N} / \mathrm{mm}^{2}\right)\end{array}$ & $\begin{array}{c}\text { Hardness } \\
(\mathrm{HV})\end{array}$ & $\begin{array}{c}\text { Thermal } \\
\text { conductivity } \\
(\mathrm{W} / \mathrm{mK})\end{array}$ & $\begin{array}{c}\text { Electrical } \\
\text { resistivity } \\
\times 10^{-7} \Omega \mathrm{m}\end{array}$ \\
\hline W70Cu30 & 3410 & 14.3 & $225 \times 103$ & 175 & 154 & 7.27 \\
\hline
\end{tabular}

Table 4. Properties of selected powders.

\begin{tabular}{cccccc}
\hline Powder & $\begin{array}{c}\text { Melting Point } \\
{ }^{\circ} \mathrm{C}\end{array}$ & $\begin{array}{c}\text { Density } \\
\mathrm{kg} / \mathrm{m}^{3}\end{array}$ & $\begin{array}{c}\text { Thermal } \\
\text { conductivity } \\
\left(\mathrm{W} \cdot \mathrm{m}^{-1} \cdot \mathrm{K}^{-1}\right)\end{array}$ & $\begin{array}{c}\text { Electrical resistivity } \\
(10 . \mathrm{E} 6 \text { Siemens } / \mathrm{m})\end{array}$ & $\begin{array}{c}\text { Powder grain } \\
\text { size }(\mathrm{nm})\end{array}$ \\
\hline Aluminum & 660 & 2700 & 238 & 36.9 & 40 \\
\hline
\end{tabular}


where $\sigma_{w}$ is fatigue limit in $\mathrm{MPa}$ and $\mathrm{HV}$ is the Vickers hardness in $\mathrm{kgf} / \mathrm{mm}^{2}$

$$
\sigma_{w}=0.5 \sigma_{u}
$$

where $\sigma_{u}$ is the ultimate tensile strength of material.

In thus study, Equation (1) was used to determine the fatigue of the specimen due to specimen shape and steel base material. The shape specimen limits the use of other fatigue testing standard like standard ASTM E606 E606M using rotating cantilever bending fatigue test machine, constant deflection amplitude cantilever bending test machine.

\subsection{Micro-Hardness Measurement}

Hardness testing determines the mechanical property of machined component. Hardness is used to estimate the ductility and resistance to wear, fatigue and tensile strength properties. Hardness may also be shown to correlate to tensile strength and fatigue in many metals. Measurement of micro-hardness was done using micro-hardness tester. ASTM E 384 standard defines and specifies the micro-indentation hardness test method and parameters of materials [19]. Hardness test uses forces in the 1 to 1000 gf. With the Vickers hardness test a diamond with top angle of $136^{\circ}$ is used. Vickers hardness parameter is presented in this research project. Tarasov et al. [20] presented in their work, the details of hardness test procedure.

\subsection{Surface Morphology of Machined Surface Analysis}

EDM is an electro-thermal process which can result in rougher or smooth surface machined surface according to machining parameters setting [21]. Surface roughness measurement using profile-meter is limited to quantify the surface in term of deviation from its original form [22]. It is important to study the surface morphology of machined surface to conform the result from profile-meter in term of image. From the surface morphology image, defects on machined surface can be characterized in terms of cracks, voids, craters, phase modification which may either be acceptable or rejected depending on the application [23]. Examination of surface morphology of machined surfaces was done on specimens machined at low and high machining parameters for each category of experiments. FESEM Zeiss SUPRA 55VP was used to examine and analyze the machined surfaces. FESEM is a microscope that uses electrons to scan in details the machined surface as compared to optical microscopy which uses light.

\section{Results and Discussions}

\subsection{Micro-Hardness of EDM on MHSS}

Figure 3 shows the trend of micro-hardness of molybdenum high speed steel after EDM process and measured using micro-hardness tester on three different locations on the machined surface. The micro-hardness of as received molybdenum high speed steel is $316.7 \mathrm{HV}$. The micro-hardness of molybdenum high speed steel after EDM is higher than the micro-hardness of bulk material as. Mi- 
cro-hardness of molybdenum high speed steel after EDM can reach $458 \mathrm{HV}$ which is increased about $44.9 \%$ from as received molybdenum high speed steel micro-hardness.

This is due to the presence of alloying elements deposited, embedded and recast layer on the machined surface.

\subsection{Fatigue Performance of EDM on MHSS}

Figure 4 shows the effect of EDM machining parameters on fatigue performance after EDM process. Fatigue performance of as received molybdenum high speed steel is about $505.60 \mathrm{MPa}$.

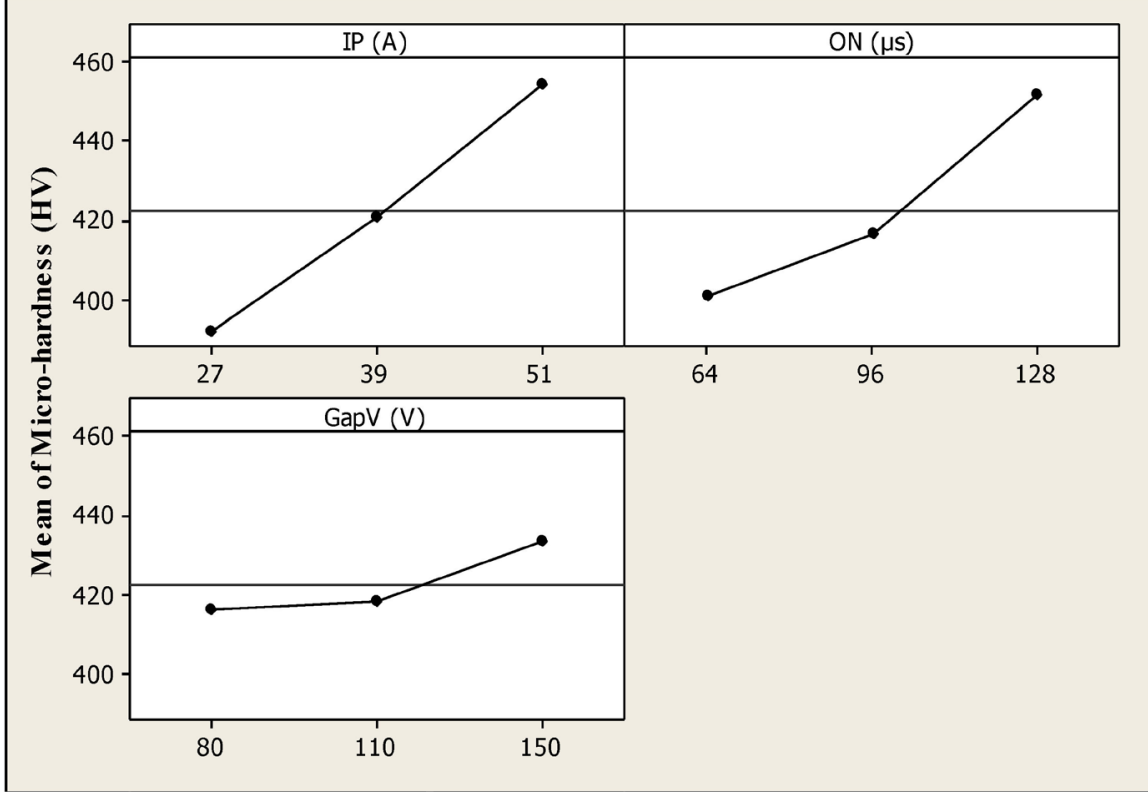

Figure 3. Micro-hardness of EDM on MHSS.

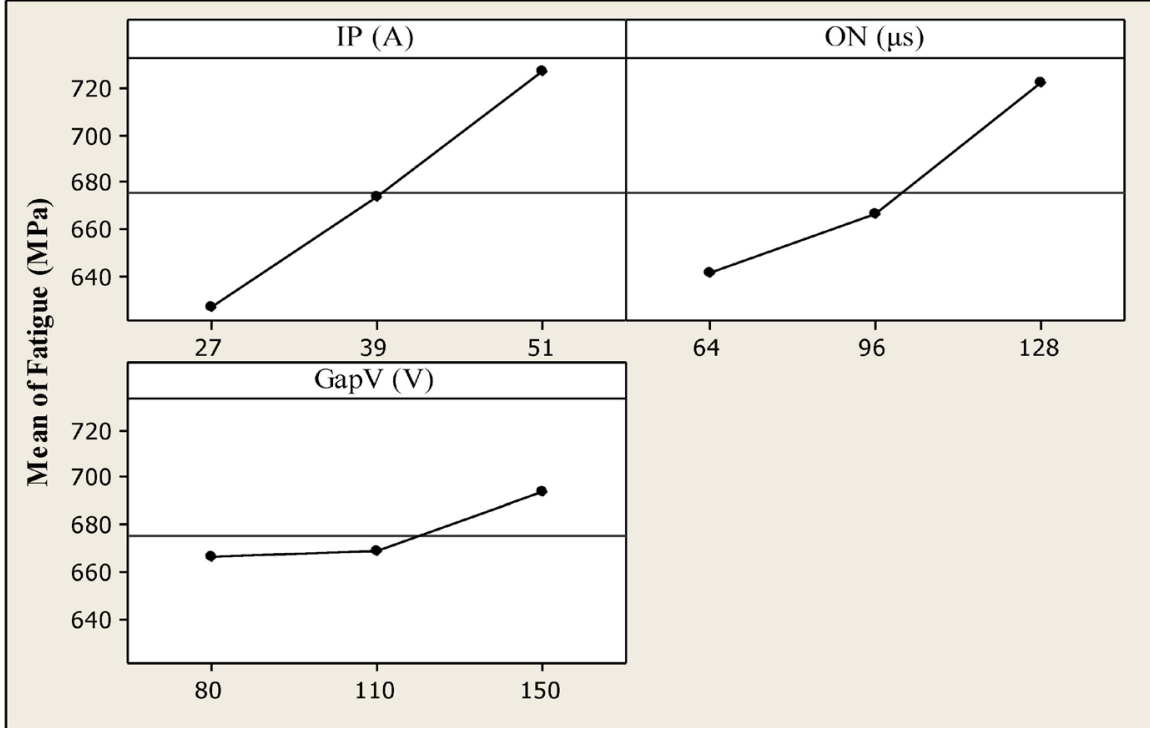

Figure 4. Fatigue of EDM on MHSS. 
Using the Equation (1), a correlation between hardness in HV and fatigue in $\mathrm{MPa}$ stated earlier, it can be found that there is a significant improvement on fatigue performance as compare to the fatigue of bulk molybdenum high speed material. Improvement of fatigue is due to the handing of the machined surface during EDM process.

\subsection{Micro-Hardness of Nano Aluminum PMEDM on MHSS}

Figure 5 shows the trend of micro-hardness of molybdenum high speed steel after PMEDM. The hardness of molybdenum high speed steel after PMEDM is significantly improvement as compared to conventional EDM shown in Figure 5. As explained above, this improvement is due to the presence of alloying elements deposited on machined surface. The hard layer containing TiC can be formed on the machined surface by EDM using titanium electrodes [24].

\subsection{Fatigue Performance of Nano Aluminum PMEDM on MHSS}

Figure 6 presents the effect of nano aluminum PMEDM machining parameters on fatigue performance. It can be found that there is a significant improvement on fatigue performance as compare to the fatigue of EDM on molybdenum high speed material. Improvement of fatigue is due to the nano aluminum embedded on the machined surface and handing of the machined surface during PMEDM process.

\subsection{Surface Morphology of Nano Aluminum PMEDM on MHSS}

Figure 7 presents the surface morphology of machined surfaces as the result of changes in IP, ON and gap voltage at low (Figure 7(a)) and high parameter setting (Figure $7(b)$ ) when machining molybdenum high speed steel with PMEDM

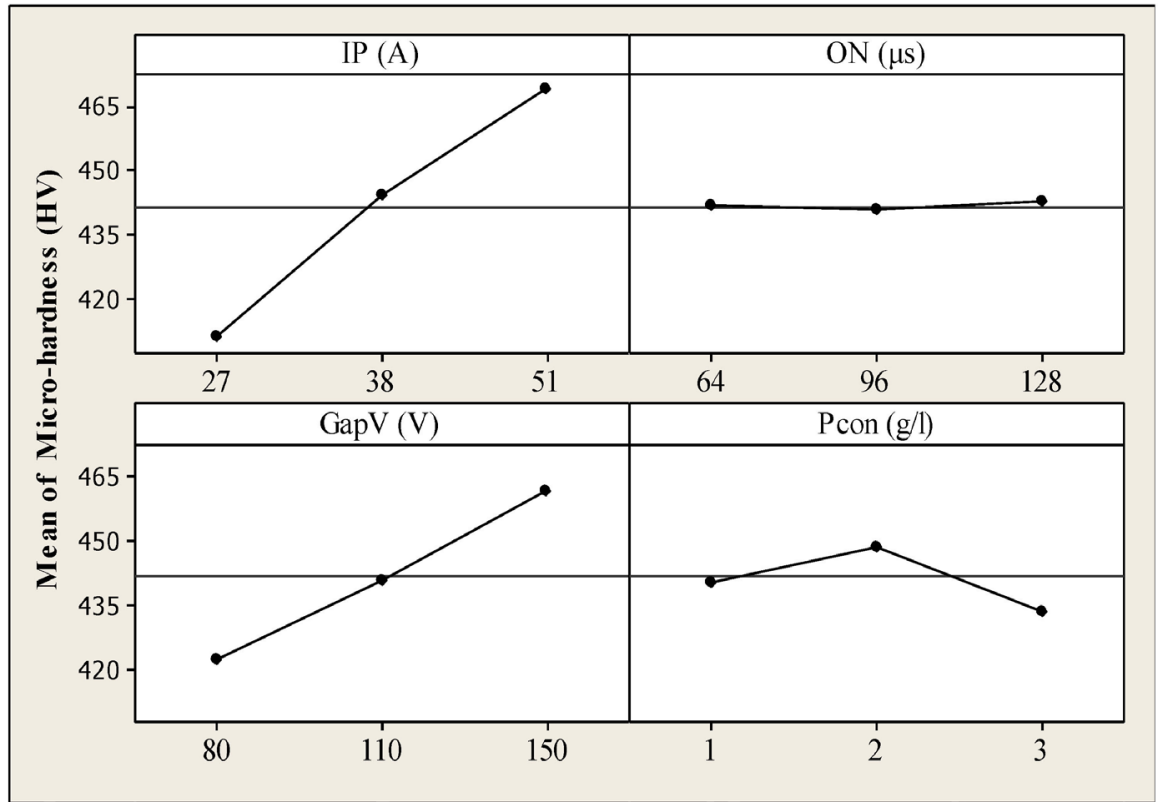

Figure 5. Micro-hardness of molybdenum high speed steel after PMEDM process. 


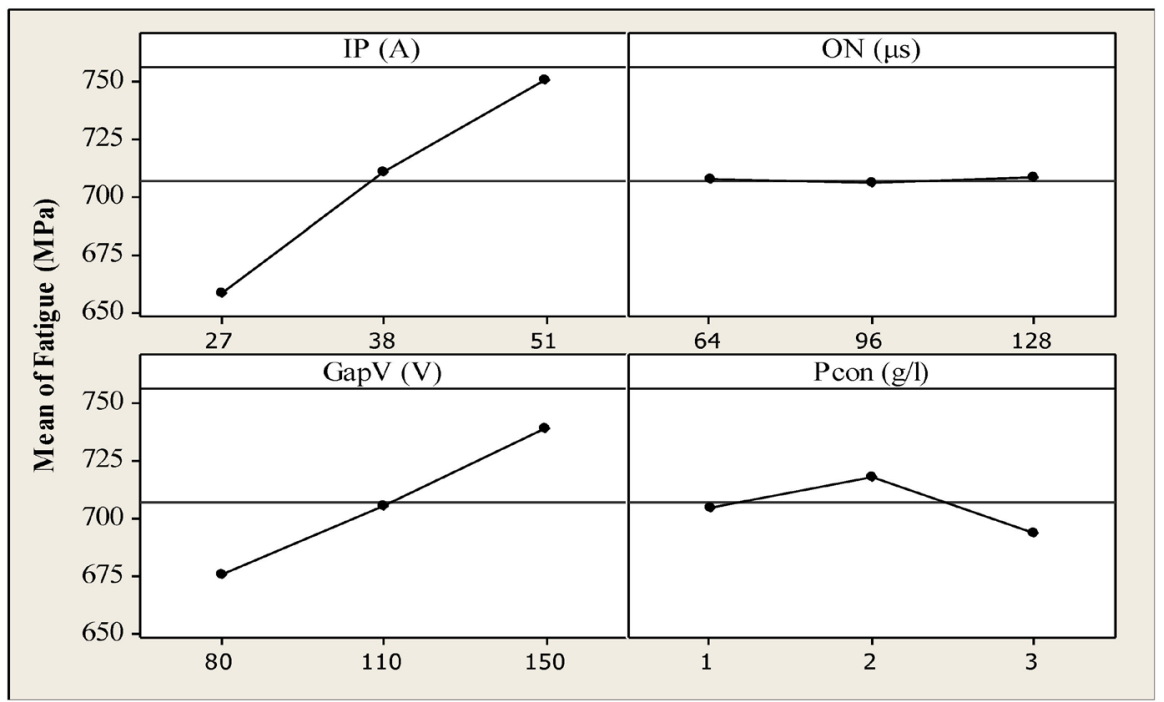

Figure 6. Fatigue performance on MHSS after PMEDM process.
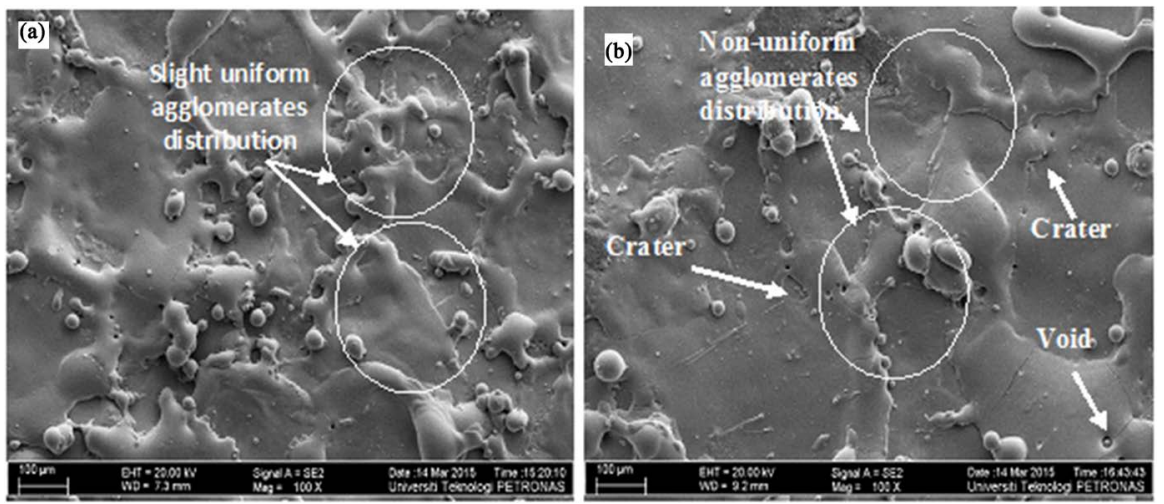

Figure 7. Surface morphology of nano aluminum PMEDM on MHSS at low parameters: $\mathrm{IP}=27 \mathrm{~A}, \mathrm{ON}=64 \mu \mathrm{s}, \mathrm{GapV}=80 \mathrm{~V}, \mathrm{Pcon}=1 \mathrm{~g} / \mathrm{l}($ Figure $7(\mathrm{a}))$ and at high machining parameters IP $=51 \mathrm{~A}, \mathrm{ON}=128 \mu \mathrm{s}, \mathrm{GapV}=150 \mathrm{~V}, \mathrm{Pcon}=3 \mathrm{~g} / \mathrm{l}($ Figure $7(\mathrm{~b}))$.

mixed. Machined surface micrograph at low peak current, ON-time and gap voltage (Figure 7(a)) shows a less rough surface. Craters, voids, and micro-cracks can be seen especially for samples machined at high peak current, ON-time and gap voltage (Figure $7(\mathrm{~b})$ ). The addition of nano aluminum particles can reduce the electrical discharge power density and gap explosive pressure, which result in smaller craters with uniform distribution.

Chrishna et al. [25], showed the influence of machining parameters on EDM of maraging steels where cracks were formed due to high thermal energy. The energy dispersive spectroscopy (EDS) spectrum characterization of molybdenum high speed steel (MHSS) is presented in Figure 8.

Figure 9 presents EDS spectrum of respected machined surfaces EDM at low (Figure 9(a)) and high (Figure 9(b)) machining parameters setting when machining molybdenum high speed steel. From Figure 9, it can be analyzed the presence of carbon, oxygen, copper and increase in alloying elements compared to as received molybdenum high speed steel (Figure 8). 


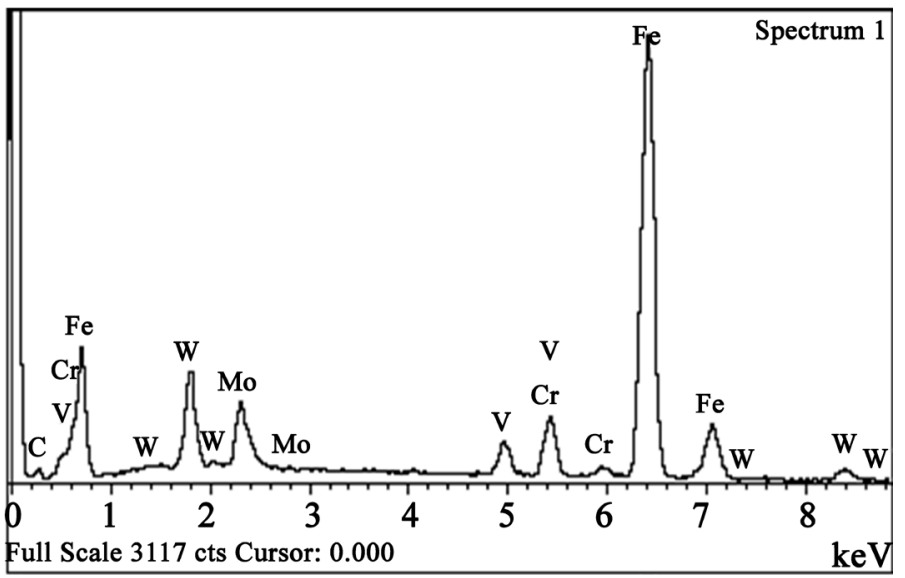

Figure 8. EDS of molybdenum high speed steel as received.

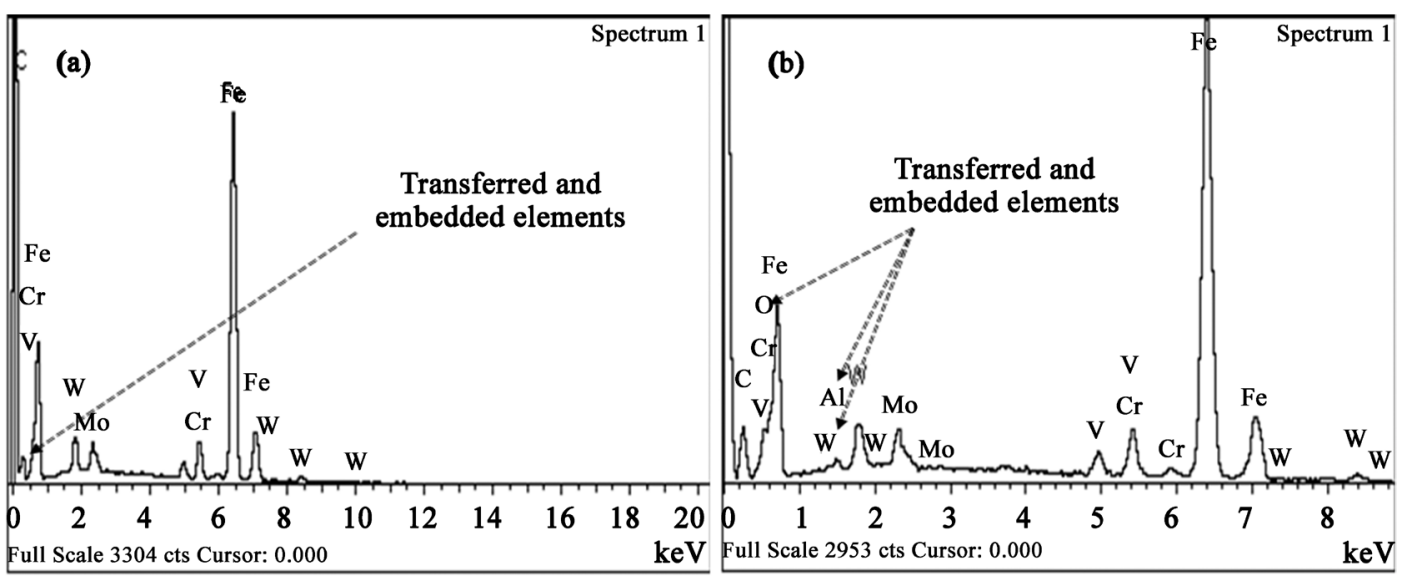

Figure 9. EDS of nano aluminum PMEDM on MHSS at low parameters: $\mathrm{IP}=27 \mathrm{~A}, \mathrm{ON}=64 \mu$ s, GapV $=80$ $\mathrm{V}$, Pcon $=1 \mathrm{~g} / \mathrm{l}($ Figure 9(a)) and at high parameters IP $=51 \mathrm{~A}, \mathrm{ON}=128 \mu \mathrm{s}, \mathrm{GapV}=150 \mathrm{~V}, \mathrm{Pcon}=3 \mathrm{~g} / \mathrm{l}$ (Figure 9(b)).

Percentage of aluminum, tungsten, and copper increase about 3.4\% compared to the based molybdenum high speed steel material. The alloying elements are transferred, deposited and embedded onto the machined surface improving the micro-hardness and the fatigue of machined surface. Kumar et al. [26] concluded in their finding that the surface modification is possible by the EDM process.

\section{Conclusion}

In this research work, analysis of fatigue and micro-hardness was done when machining molybdenum high speed steel in nano aluminum PMEDM for biomedical and industrial applications. The use of nano aluminum in PMEDM on molybdenum high speed steel results in improving fatigue and micro-hardness as compared to conventional EDM. This is attributed due to transfer of alloying deposited elements and uniform distribution of particles from nano aluminum onto the workpiece machined surface. The created carbon enriched surface layer also improves the properties of workpiece machined surface. 
Further analysis on crack initiation, crack growth and osteointegration will be useful in order to establish the potential used of PMEDM for biomaterials.

\section{Acknowledgements}

Authors thank the Universiti Teknologi PETRONAS for funding this research trough ERGS grant.

\section{Conflicts of Interest}

The authors declare no conflicts of interest regarding the publication of this paper.

\section{References}

[1] Kansal, H., Singh, S. and Kumar, P. (2007) Effect of Silicon Powder Mixed EDM on Machining Rate of AISI D2 Die Steel. Journal of Manufacturing Processes, 9, 13-22. https://doi.org/10.1016/S1526-6125(07)70104-4

[2] Zhang, Y., Liu, Y., Shen, Y., Ji, R., Cai, B., Li, H., et al. (2012) A Review of the Current Understanding and Technology of Powder Mixed Electrical Discharge Machining (PMEDM). 2012 International Conference on Mechatronics and Automation (ICMA), Chengdu, 5-8 August 2012, 2240-2247.

[3] Singh, B., Kumar, J. and Kumar, S. (2016) Investigation of the Tool Wear Rate in Tungsten Powder-Mixed Electric Discharge Machining of AA6061/10\% $\mathrm{SiC}_{\mathrm{p}} \mathrm{Com}-$ posite. Materials and Manufacturing Processes, 31, 456-466. https://doi.org/10.1080/10426914.2015.1025965

[4] Kuriachen, B. and Mathew, J. (2016) Effect of Powder Mixed Dielectric on Material Removal and Surface Modification in Microelectric Discharge Machining of Ti-6Al-4V. Materials and Manufacturing Processes, 31, 439-446. https://doi.org/10.1080/10426914.2015.1004705

[5] Zhao, W., Meng, Q. and Wang, Z. (2002) The Application of Research on Powder Mixed EDM in Rough Machining. Journal of Materials Processing Technology, 129, 30-33. https://doi.org/10.1016/S0924-0136(02)00570-8

[6] Singh, S., Maheshwari, S., Dey, A. and Pandey, P. (2010) Experimental Results and Analysis for Electrical Discharge Machining (EDM) of Aluminium Metal Matrix Composites with Powder-Mixed Dielectric: Lenth's Method. International Journal of Manufacturing Technology and Management, 21, 67-82. https://doi.org/10.1504/IJMTM.2010.034287

[7] Özerkan, B. and Çoğun, C. (2010) Effect of Powder Mixed Dielectric on Machining Performance in Electric Discharge Machining (EDM). Gazi University Journal of Science, 18, 211-228.

[8] Singh, S., Maheshwari, S. and Pandey, P. (2006) An Experimental Investigation into Abrasive Electrical Discharge Machining (AEDM) of $\mathrm{Al}_{2} \mathrm{O}_{3}$ Particulate Reinforced Al-Based Metal Matrix Composites. Journal of Mechanical Engineering, 7, 13-33.

[9] Nanimina, A.M., Bongo, D., Lamaï, N., et al. (2020) Characterization and Analysis of Biomedical Grade Alloy Machined Surface in Aluminum Powder Mixed EDM. International Journal of Engineering Sciences \& Research Technology, 9, 124-129.

[10] Singh, S., Singh, H., Singh, J. and Bhatiac, R. (2011) Effect of Composition of Powder Mixed Dielectric Fluid on Performance of Electric Discharge Machining. National Conference on Advancements and Futuristic Trends in Mechanical and 
Materials Engineering, Jalandhar, January 2011.

[11] Ojha, K., Garg, R. and Singh, K. (2011) Experimental Investigation and Modeling of PMEDM Process with Chromium Powder Suspended Dielectric. International Journal of Applied Science and Engineering, 9, 65-81.

[12] Singh, A.K., Kumar, S. and Singh, V. (2014) Effect of the Addition of Conductive Powder in Dielectric on the Surface Properties of Superalloy Super Co 605 by EDM Process. The International Journal of Advanced Manufacturing Technology, 77, 99-106. https://doi.org/10.1007/s00170-014-6433-Z

[13] Tran, T.-H., Nguyen, M.-C., Luu, A.-T., Le, T.-Q., Vu, T.-T., Tran, N.-G., et al. (2020) Electrical Discharge Machining with SiC Powder-Mixed Dielectric: An Effective Application in the Machining Process of Hardened 90CrSi Steel. Machines, 8, 36. https://doi.org/10.3390/machines 8030036

[14] Annarao, S.R. and Selokar, G. (2020) Research on Die Steel Machinability Using Powder Mixed Electric Discharge Machining (PMEDM). Journal of Critical Reviews, 7, 1862-1868.

[15] Ahmad, S., Lajis, M.A., Haq, R.H.A., Arifin, A.M.T., Rahman, M.N.A., Haw, H.F., et al. (2018) Surface Roughness and Surface Topography of Inconel 718 in Powder Mixed Dielectric Electrical Discharge Machining (PMEDM). International Journal of Integrated Engineering, 10, 181-186.

[16] Opoz, T., Yasar, H., Murphy, M.F., Ekmekci, N. and Ekmekci, B. (2019) Ti6Al4V Surface Modification by Hydroxyapatite Powder Mixed Electrical Discharge Machining for Medical Application. International Journal of Advances in Engineering and Pure Sciences, 31, 1-10. https://doi.org/10.7240/jeps.450383

[17] Sidhom, H., Ghanem, F., Amadou, T., Gonzalez, G. and Braham, C. (2013) Effect of Electro Discharge Machining (EDM) on the AISI316L SS White Layer Microstructure and Corrosion Resistance. The International Journal of Advanced Manufacturing Technology, 65, 141-153. https://doi.org/10.1007/s00170-012-4156-6

[18] Casagrande, A., Cammarota, G. and Micele, L. (2011) Relationship between Fatigue Limit and Vickers Hardness in Steels. Materials Science and Engineering. A, 528, 3468-3473. https://doi.org/10.1016/j.msea.2011.01.040

[19] (1999) ASTM E384 Standard Test Method for Microhardness of Materials. American Society for Testing and Materials ASTM, Annual Book of Standards, 3.

[20] Tarasov, L. and Thibault, N. (1947) Determination of Knoop Hardness Numbers Independent of Load. Transactions of the American Society of Metals, 38, 331-353.

[21] Ekmekci, B. and Ersöz, Y. (2012) How Suspended Particles Affect Surface Morphology in Powder Mixed Electrical Discharge Machining (PMEDM). Metallurgical and Materials Transactions B, 43, 1138-1148. https://doi.org/10.1007/s11663-012-9700-0

[22] Nanimina, A.M.N. (2010) Machinability of Aluminium Metal Matrix Composite Reinforced with Alumina Using Electro-Discharge Machining. Master Thesis, Universiti Teknologi PETRONAS.

[23] Pradhan, M. and Biswas, C. (2012) Optimisation of Surface Integrity Model Using Response Surface Methodology for EDMed AISI D2 Tool Steel. International Journal of Mechatronics and Manufacturing Systems, 5, 340-360. https://doi.org/10.1504/IJMMS.2012.049967

[24] Uno, Y., Okada, A. and Cetin, S. (2001) Surface Modification of EDMed Surface with Powder Mixed Fluid. 2nd International Conference on Design and Production of Dies and Molds, Kuşadası, Okayama, 33-45.

[25] Rao, G.K.M., Satyanarayana, G. and Praveen, M. (2008) Influence of Machining 
Parameters on Electric Discharge Machining of Maraging Steels-An Experimental Investigation. Proceedings of the World Congress on Engineering, London, 2-4 July 2008.

[26] Kumar, S. and Batra, U. (2012) Surface Modification of Die Steel Materials by EDM Method Using Tungsten Powder-Mixed Dielectric. Journal of Manufacturing Processes, 14, 35-40. https://doi.org/10.1016/j.jmapro.2011.09.002 